\begin{tabular}{|l|l|}
\hline Postprint Version & 1.0 \\
\hline Journal website & http://www.sciencedirect.com/science/article/pii/S0738399111005738 \\
\hline Pubmed link & http://www.ncbi.nlm.nih.gov/pubmed/22178391 \\
\hline DOI & 10.1016/j.pec.2011.11.010 \\
\hline
\end{tabular}

This is a NIVEL certified Post Print, more info at http://www.nivel.eu

\title{
Attitudes and dilemmas of caregivers supporting people with intellectual disabilities who have diabetes
}

\author{
MIEKE CARDOL ${ }^{\mathrm{A},}$, MIEKE RIJKEN ${ }^{\mathrm{A},}$, HENNY VAN SCHROJENSTEIN LANTMAN-DE VALK ${ }^{\mathrm{B},}$ \\ ${ }^{a}$ NIVEL (Netherlands Institute for Health Services Research), Utrecht, The Netherlands \\ ${ }^{b}$ Department of Primary and Community Care, Radboud University Nijmegen Medical Centre, The \\ Netherlands
}

\begin{abstract}
Objective: To explore how professional caregivers in communal living arrangements support people with a mild or moderate intellectual disability (ID) who have diabetes.

Methods: A qualitative study, 13 caregivers participated in semi-structured interviews.

Results: Professional caregiver support in diabetes care is almost solely directed towards administering medication and controlling food intake. Caregivers want to provide personcentered care but are hindered by a conflict between protecting a client's health and at the same time respecting autonomy. None of the caregivers had received training in supporting selfmanagement; their knowledge about diabetes is limited. The few that engaged their client in self-management stressed the importance of a positive and collaborative approach.

Conclusion: This study provides a first insight into the challenges that professional caregivers experience when a client with ID has diabetes. More education for caregivers seems needed. Self-management support is likely to benefit from consensus among caregivers about what comprises person-centered care and self-management in people with ID who have a chronic disease.

Practice implications: Increasing caregivers' awareness of the importance of supporting selfmanagement in people with ID and a chronic disease is essential. Discussing practice examples in the light of existing knowledge about developing autonomy will contribute to their awareness.
\end{abstract}

\section{INTRODUCTION}

Diabetes is prevalent among people with intellectual disability (ID). In a Dutch study of people with ID a prevalence of $11 \%$ was found as compared to $6 \%$ in people without ID [1]. Every day people with diabetes need to undertake activities to manage their condition. This is called self-management and involves understanding and following a medical regimen, making challenging changes in lifestyle and dealing with the emotions arising from having a chronic illness [2] and [3]. Self-management does not mean that people have to go it alone. Self-management support is the assistance professional caregivers give patients and their self-defined circle of support so that they can manage their chronic condition on a day-to-day basis and develop the confidence to sustain healthy behaviors [4]. Effective self-management support goes beyond telling people what to do. It involves taking into account a person's needs as well as providing opportunities to learn and to increase beliefs in one's capabilities [2]. Taking into account a person's needs 
implies that partial self-management is also an option, for example in people with ID who cannot or do not wish to exercise complete control over the management of their condition. Therefore, self-management never is an ultimate goal, it is a means to develop and maintain well-being.

Diabetes management mainly takes place in the home environment and not in a medical setting. In the Netherlands, most people with ID live in community housing, in which professional caregivers provide support related to daily living [5]. In general, these caregivers are social workers; they are not trained to support clients with a chronic disease such as diabetes.

In recent decades policy concerning the care for people with ID has developed from normalization, i.e. living conditions as close as possible to the regular circumstances (deinstitutionalization), towards inclusion, autonomy and quality of life, i.e. supported living and individualization [6]. This has led to new approaches in care. Important incentives for these changes involved modified opinions about what constitutes 'good care' and a 'good quality of life'. Nowadays, patient-centeredness, autonomy and selfdevelopment are important aspects in care [7] and [8]. For the caregivers in (communal) living arrangements new roles presented themselves along with these changes, with the emphasis shifting from care towards support and coaching [9] and [10]. The question should not be 'what is needed?' but rather 'what are the needs of this person?' However, it is not as easy as that in reality, especially not in case of a chronic illness. A central issue associated with the support of people with ID and chronic illness is the dilemma of creating room and opportunity for autonomy on the one hand and providing good care and protection if needed on the other hand [9] and [11]. Further, it is pointed out that exercising autonomy can be difficult for people who are dependent on care and at the same time addressed as clients [12] and [13]. Likewise for people with ID, new roles have presented themselves. For the professionals the question is how to create conditions for exercising autonomy and encouraging self-management in people who are not familiar with these roles.

Professional caregivers have been relatively neglected as a focus for research in the field of intellectual disability services [14]. No studies have been conducted to explore staff's knowledge and perceptions related to supporting someone with ID that has diabetes, whereas their support is essential for people with diabetes to learn and develop self-management skills and to deal with the consequences of the disease in daily life. In the present study we will explore qualitatively the role of professional caregivers in providing support to people with a mild or moderate ID who have diabetes.

\section{METHODS}

\subsection{Participants}

The participants in this study were professional caregivers in living arrangements recruited via the members of the "Living Together" Panel. This is a national panel of people in the Netherlands with mild or moderate ID and their relatives. The panel is representative with regard to age, gender and distribution between people with mild and moderate disabilities [5]. Members of the panel with ID live in community housing or other living arrangements for people with ID; a small number live independently with or without professional care. At the time of this study, in 2010, the panel consisted of 630 people with ID. Twenty-four persons with ID had diabetes. They were identified in a previous panel assessment by themselves or their relatives with help of a general question about the presence of diseases. The names of 13 regular caregivers were provided by the panel members with diabetes or their relatives; the other 11 panel members with diabetes did not live in community housing and were supported by their family. The regular professional caregivers received information about the research by mail and were approached by telephone by the researcher (MC). All caregivers agreed to participate in the study.

\subsection{Interviews}

We conducted face-to-face interviews with professional caregivers who support the people with diabetes in community housing. We interviewed 13 caregivers. Nine caregivers, seven women and two men, were qualified and experienced social workers (>5 years) in the care for people with ID; one woman was a trainee in this field. Three other female caregivers were qualified nurses. Eleven caregivers worked in small community houses; two worked in a residential facility.

The interviews were semi-structured. The interview format consisted of four main questions: how do caregivers support individuals with diabetes, how do they provide opportunities for self-management, what 
problems do they encounter, and do they themselves need support in supporting the people with ID and diabetes.

All interviews were completed by the first author (MC). Almost all interviews lasted 40-60 min.

\subsection{Analysis}

The interviews were audio recorded and the tapes were transcribed verbatim. Thematic analysis was conducted using strategies from grounded theory. First, conceptual labels were given to groupings of similar phenomena (open coding) related to the research questions, for example 'perceptions about diabetes' or 'way of providing support' [15]. In the second phase (axial coding) minor concepts were related to broader level concepts. For example, 'educational material' and 'living arrangement' were related to 'contextual factors'. A team of two researchers (MC, MR) evaluated the interviews, discussed the data and the codes, and made comparisons. Data analysis was iterative so that the later interviews enabled us to test and further explore themes from the initial analysis. Using the criteria generated from the discussion process as a guide, the first author then completed the analysis. The software package MaxQDA 2007 was used to analyze the data.

\section{RESULTS}

Four inter-related themes that have an impact on diabetes support emerged from the analyses: person with diabetes, knowledge and educational needs of the caregiver, finding a mode, and contextual factors (Box 1).

\section{[воX 1]}

\subsection{Person with diabetes: perceived severity of diabetes}

Eleven caregivers did not perceive diabetes as a serious disease. Only if a person has to take insulin injections or if there is a possibility that they might lose consciousness, is it perceived to be more serious.

"It is just a condition of her old age, due to her weight." (nurse13/client with moderate ID)

"It's serious only if she has a hypo. I think that sometimes her blood glucose level is really too low, at times we cannot wake her up.... that's how diabetes manifests itself." (social worker3/client with moderate ID)

\subsection{Perceptions regarding motivation and capability of person with diabetes}

All professional caregivers showed compassion for the difficulties persons with diabetes are confronted with in daily life, especially in relation to food intake. On the other hand, they also gave examples of situations when they did not trust the client with diabetes. These situations mainly involved eating in secret, stealing food, and lack of responsiveness.

"He forces others to hand over food too....he always tries to get others to butter a couple of extra sandwiches for him and the food disappears from the table, just like that." (social worker4/client's level of ID unknown)

She didn't react at all - dead scary - but she heard everything. She disconnects herself it seems, to create distance from all daily business. Whether it has to do with diabetes, I actually don't know”. (social worker2/client with moderate ID)

Caregivers were not always convinced that their clients with diabetes were motivated to be engaged in self-management activities. This was thought to be due to traits of character or a lack of interest in healthrelated issues.

"She has been to school, she can read and write, but diabetes does not interest her at all". (social worker9/client with mild ID)

"Basically she's a bit lazy, I think. She finds it easy to let others do things for her. She is passive, difficult to move. That is simply her character." (social worker7/client with mild ID)

Nine caregivers were rather negative about the capability of the person with diabetes to learn and selfmanage diabetes to some extent.

"She would never be able to learn it herself - to inject insulin - she is too dependent on us for that. To fine-tune the doses, there are too many operations needed, she could never do that". (social worker8/client with moderate ID) 
"I don't think he could do that himself, he lacks intellectual ability, I also think he would be too lazy and that he doesn't know how insulin works. He will never learn anything.” (social worker6/client with moderate ID)

\subsection{Knowledge and educational needs of the caregivers}

Knowledge about diabetes varies. Nurses have more knowledge than social workers. Most social workers underwent additional training to learn about diabetes. These short courses took a couple of hours and focused on the different types of insulin and how to inject. After the training the caregiver was authorized to give injections. Supporting diabetes self-management was not part of the training. Sometimes a colleague who is a certified nurse gave the training.

"You learn all the necessary stuff: injecting, assessment of blood glucose values and taking action: injecting." (social worker5/client with moderate ID)

To what extent training was offered varied; it sometimes fully depended on the initiative of the caregiver. In two cases training was impeded by managers. Nevertheless, most caregivers did not have a need to learn more about diabetes, while at the same time they mentioned several dilemmas. Some respondents wanted to learn more about diabetes; others felt comfortable because they always have access to a physician in case something should go wrong.

"Once, a resident had fallen out of bed and appeared to be unconscious. You immediately think of something else - did not think of diabetes. Even though I knew he had diabetes - he had medication for it. How stupid of me - just didn't think of it.” (social worker3/client with moderate ID)

"If there is something we're concerned about, that's no problem, we just call the general practitioner." (social worker1/client with moderate ID)

"We lack the basic medical knowledge, there are only a few qualified nurses. That's why we frequently call on a physician. (trainee/client with moderate ID)

\subsection{Finding a mode: self-management support}

In general, the client's diabetes did not constitute a prominent feature in the support caregivers provide. If the person needed insulin, the care tended to be perceived as more intensive.

"Of course in the beginning it's different, for a while, you are facing a person with ID and in addition to that diabetes, that's two separate things. But there comes a time when we look on it as one trajectory. It's troublesome when they have it, but not insurmountable, let me put it like that." (social worker9/client with mild ID)

The caregivers who were qualified nurses mentioned they were more attentive towards a client with diabetes:

"Diabetes involves support with practical things such as injecting insulin, and we are more attentive towards her health. Because of her diabetes she has a risk for increased blood pressure, so we keep an eye on that. Also, she can be somewhat more tired; if she wants to take a nap in the chair we don't disturb her." (nurse12/client with mild ID)

"If you have to inject insulin, you are more on the alert. It makes the support a bit more demanding." (nurse11/client with moderate ID)

When asked about the special care or support they provided in relation to the diabetes, all caregivers cited medical management (injections, blood glucose tests) and controlling food intake. Some also mentioned support in teaching how to deal with dietary rules:

"We can take away everything for him, but when he visits his friends or parents, the situation will be different. So, you try to teach him to deal with the situation. Here at home we facilitate and protect him, but we also teach him to deal with difficulties he may encounter elsewhere.” (trainee/client with moderate ID)

It was not clear for the professionals who bears the responsibility for the diabetes management of a person with ID. Mostly, caregivers regarded themselves as being responsible; often the physician was also held responsible. Two caregivers regarded the manager as responsible and two others regarded the person with diabetes as also being responsible.

In general, the way the professional caregivers provided support was more directed towards control and prohibition, than towards developing self-efficacy and autonomy. The four caregivers who had a positive attitude towards the learning ability of the individuals with ID spoke of trust and a positive approach as key components of their support. To compliment someone on something works better than to tell them what they should not have done. They gave examples of how they had tried to increase the confidence of the 
person with ID and to engage him/her in self-management activities. Creative solutions and flexibility provide opportunities to engage the person with ID in diabetes management.

"Last week was her birthday, we organized a "lite" party. Together we bought strawberries and made delicious salads". (social worker1/client with moderate ID)

"H. needs a lot of insulin, which for her makes it difficult to inject herself, because her hands are bothering her. Now we do it in two goes, so she doesn't need to put so much effort into it.” (nurse12/client with mild ID)

Personal goal setting, appointments and structure emerge from the interviews as additional important aspects of support. Impeding and facilitating factors related to providing diabetes support as mentioned by the respondents are listed in Table 1 . The table shows that facilitating self-management involves a structured and developmental approach. Contextual factors of importance are consistency within the team as well as collaboration with health care professionals and family. Impeding contextual factors for selfmanagement support are a lack of diabetes education material, other residents in the community housing that need a lot of attention, and diabetes material such as an indicator for blood glucose level that does not work properly.

\section{[TABLE 1]}

\subsection{Finding a mode: balancing health management and quality of life}

The caregivers indicated they wanted to be person-centered in their support, but they described dilemmas of providing good diabetes care as opposed to person-centered care, especially in relation to food intake.

"We can control her very precisely. But that's not support, that would be control and she would have no life.” (social worker9/client with mild ID)

"For his health the best thing would be to be in a closed institution, where all the food is controlled and he cannot go out. But his life would not be pleasant then.” (social worker6/client with moderate ID)

Whether their support was more directed towards health protection or well-being depended on a person's health status and behavior more than on the severity of the ID. Most professionals seemed to define personcenteredness as the ultimate freedom of choice of doing as one wants. They address the meaning of the concept of person-centered care: "If someone functions as a three year old, how can he decide for himself what is good for him?” (social worker2/client with moderate ID)

A few caregivers were less black and white and focused on clarifying a person's wants as a starting point for negotiation and consent to encourage autonomy and partial self-management.

"She wanted to go to the village by herself. Previously, this was not allowed because she sometimes stole food from the shops. ... We made a plan, practiced together and succeeded. Now she does some shopping for us, and buys her own healthy desserts. Sometimes it goes wrong, then we talk about it. She is so proud of doing this." (social worker1/client with moderate ID)

In Table 2, the different ways the professional caregivers provided support related to food intake were organized along the extent to which the individual with diabetes is informed and engaged. Most of the time, the initiative was left with the caregivers, whereas the person with diabetes was informed ("not good for you") and the kitchen cabinets were closed. Informing and engaging the person in self-management is rare. In one case, the caregiver had handed over the initiative to the person with diabetes, but it was stressed this occurred only because the client was in good health.

\section{[TABLE 2]}

\section{DISCUSSION AND CONCLUSION}

\subsection{Discussion}

To maintain optimum well-being, people with ID who have diabetes need support. To our knowledge, this is the first study that provides insights into the challenges that professional caregivers experience in providing this support. 
Only 24 persons in our panel had diabetes (4\%), which is less than the prevalence rate in the Netherlands. Probably the prevalence of diabetes among the panel members is higher and the low rate was caused by the openness of the question asked. Although the number of interviews conducted was limited and the results cannot be generalized to the support given by all caregivers in communal sheltered housing, we were able to draw some conclusions.

This study shows that self-management support in diabetes care provided by caregivers in sheltered housing is mostly directed towards taking medication and controlling food intake. By contrast, interviews with people with ID who have diabetes show that they also have needs related to dealing emotionally with the illness and that they have questions about their future [16]. Furthermore, examples of engagement by people with ID in self-management activities show that this contributes to their wellbeing [16]. A small proportion of the caregivers in this study gave examples of supporting the development of autonomy and self-management, i.e. providing opportunities to learn and develop ways to deal with new situations. The basis of their support consisted of trust, consistency and collaboration. Although all caregivers stressed that they wanted to provide person-centered care, it was difficult to succeed in doing so. Most of them were bothered by the dilemma between providing good care, such as preventing a person from unhealthy eating, and at the same time providing person-centered care and respecting the autonomy of the person with diabetes, as described in the literature [9], [11] and [17]. In general, their solution to solve the dilemma is to take over. However, this kind of support impedes people with ID from developing their own engagement and self-efficacy in diabetes management.

The results may not come as a surprise given the fact that the professional caregivers were not educated to support diabetes self-management; they had merely learned some extra medical skills. In addition, they did not regard diabetes as a serious disease. It can be questioned whether diabetes education for caregivers in sheltered housing should remain as basic and lacking accountability as is currently the case. This applies not only to diabetes, but probably also to other chronic conditions. The caregivers report dilemmas that can cause tension in the patient-professional relationship, and they also describe situations in which the persons with ID are exposed to health risks, such as frequent high or low blood glucose levels. The caregivers in this study are not unique. In an Australian study among health professionals from a range of service types two thirds had received no training in self-management support techniques [18]. Also studies about other health conditions stress the need for more education of caregivers [19] and [20]. The few caregivers in this study who did engage persons with ID in self-management stressed the importance of a consistent and positive approach. This calls for dialogue and for creativity and flexibility on the part of the caregivers. Professionals need skills to engage with patients as partners in care and they need a collective vision on support. Further, a shift to self-management support needs to be underpinned by the system the caregivers are working in [21]. The prevalence of chronic disease in people with ID is increasing because of population ageing [22]. Therefore, in living arrangements for people with ID, supporting self-management of people with a chronic illness should be integral to the vision of good care.

Self-management programs for people with ID and a chronic disease do not exist. This also goes for educational material about diabetes that people with ID can understand [16] and that caregivers can use to initiate dialogue about self-management [18]. Given the dilemmas experienced by the caregivers, it seems that first the meaning of self-management in the context of people who cannot or do not wish to exercise some control over their physical health needs to be explored further. Self-management may be too closely associated with the idea of independence [23], which does not fit the reality of people with ID.

\subsection{Conclusion}

Caregivers want to provide person-centered care, but they often do not know how to involve the person with ID in the management of diabetes and what to do when person-centered care and respect for autonomy conflict with caring for a person's health. Education for professional caregivers about diabetes and selfmanagement support can benefit the patient-caregiver relationship. Further, the collective vision on good care should also involve consensus about what comprises self-management support in people with ID who have a chronic disease. After all, self-management is not the ultimate goal, it is a means to develop and maintain well-being.

\subsection{Practice implications}

How to create conditions for exercising autonomy and encouraging self-management in people who are not familiar with doing so? Agich describes the importance of not striving for an ideal state of autonomy as in independence. Rather, autonomy should be seen as something all individuals can develop; it is a 
personally unique characteristic which exists in different degrees, depending on a person's circumstances [17]. Van Hooren et al. recommend taking the caregiver-patient relationship as a starting point. They stress that deliberation is not only a process of rational arguments, it is also important to "find new perspectives by opening up one's horizon in response to others" [11]. Discussing practice examples like we did in this paper and talking about what person-centered care consists of may benefit from input regarding what is known about developing autonomy in individuals with ID [11], [17] and [24]. Discussing practice examples will help to raise awareness of the problem and the importance of engaging people with ID in diabetes management in a way that fits their needs and possibilities.

\section{ACKNOWLEDGEMENTS}

The authors of this study wish to thank the professional caregivers who were willing to participate in this research, and the Dutch Diabetes Research Foundation for its financial support.

\section{REFERENCES}

[1] J.M.J.A.A. Straetmans, H.M.J. Van Schrojenstein Lantman-De Valk, F.G. Schellevis and G. Dinant, Health problems of people with intellectual disabilities: the impact for general practice. Brit J Gen Pract, 57 (2007), pp. 64-66.

[2] K. Lorig and H. Holman, Self-management education: history, definitions, outcomes, and mechanisms. Ann Behav Med, 26 (2003), pp. 1-7.

[3] H. Hollman and K. Lorig, Patient self-management: a key to effectiveness and efficiency in care of chronic disease. Public Health Rep, 119 (2004), pp. 239-243.

[4] T. Bodenheimer, K. MacGregor and C. Sharifi, Helping patients manage their chronic conditions, California Health Care Foundation, California (2005).

[5] J.C.E. Dusseljee, P.M. Rijken, M. Cardol, L.M.G. Curfs and P.P. Groenewegen, Participation in daytime activities among people with mild or moderate intellectual disability. J Intell Disabil Res, 55 (2010), pp. 4-18.

[6] A.T.H.G. Van Gennep, Paradigma-verschuiving in de visie op zorg voor mensen met een verstandelijke handicap, University Maastricht, Maastricht (1997).

[7] R.J. Stancliffe, Community living-unit size, staff presence, and residents' choice-making. Ment Retard, 35 (1997), pp. 1-9.

[8] C. Sohl, G. Widdershoven and J. Van der Made, Autonomie van mensen met een verstandelijke handicap. Maandblad Geestelijke volksgezondheid, 52 (1997), pp. 858-865.

[9] P. Embregts, Lectureship 'Care for people with intellectual disability', Hogeschool van Arnhem en Nijmegen, Nijmegen (2009).

[10] J. Van Loon and G. Van Hove, Professionaliteit van de support werker: van kwaliteit van zorg naar kwaliteit van bestaan, W.H.E. Buntix, A. Van Gennep, Editors, Professionaliteit in de hulpverlening aan mensen met verstandelijke beperkingen, Garant, Antwerpen/Apeldoorn (2007), pp. 55-75.

[11] R.H. Van Hooren, G.A.M. Widdershoven, H.W. Van den Borne and L.M.G. Curfs, Autonomy and intellectual disability: the case of prevention of obesity in Prader-Willi syndrome. J Intell Disabil Res, 46 (2002), pp. 560-568.

[12] J.C. Tronto, Moral boundaries; a political argument for an ethic of care, Routledge, New York/London (1993).

[13] M. Cardol, B.A. De Jong and C.D. Ward, On autonomy and participation in rehabilitation. Disabil Rehabil, 18 (2002), pp. 970-974.

[14] R.P. Hastings, Support staff working in intellectual disability services: the importance of relationships and positive experiences. J Intell Dev Disabil, 35 (2010), pp. 207-210.

[15] J. Corbin and A. Strauss, Basics of qualitative research; techniques and procedures for developing grounded theory, Sage Publications, California (2008).

[16] M. Cardol, M. Rijken and H.M.J. Van Schrojenstein Lantman-De Valk, People with mild to moderate intellectual disability talking about their diabetes and how they manage. J Intell Disabil Res, (2011).

[17] G.J. Agich, Autonomy and long-term care, Oxford University Press, New York/Oxford (1993).

[18] A.J. Lake and P.K. Staiger, Seeking the views of health professionals on translating chronic disease self-management models into practice. Patient Educ Couns, 79 (2010), pp. 62-68.

[19] B.E. McGuire and A.A. Bayley, Relationships, sexuality and decision-making capacity in people with an intellectual disability. Curr Opin Psychiatr, (2011).

[20] L. Taggart, R. McMillan and A. Lawson, Staff's knowledge and perceptions of working with women with intellectual disabilities and mental health problems. J Intell Disabil Res, 54 (2010), pp. 90-100. 
Cardol, M., Rijken, M., Schrojenstein Lantman-de Valk, H. van. Attitudes and dilemmas of caregivers supporting people with intellectual disabilities who have diabetes. Patient Education and Counseling: 2012 ,

[21] T. Kielmann, G. Huby, A. Powell, A. Sheikh, D. Price and S. Williams, et al. From support to boundary: a qualitative study of the border between self-care and professional care. Patient Educ Couns, 79 (2010), pp. 55-61.

[22] M.P. Janicki, P.W. Davidson, C.M. Henderson, P. McCallion, J.D. Taets and L.T. Force, et al. Health characteristics and health service utilization in older adults with intellectual disability living in community residences. J Intell Disabil Res, 46 (2002), pp. 287-298.

[23] S. Lawn, J. McMillan and M. Pulvirenti, Chronic condition self-management: expectations of responsibility. Patient Educ Couns, (2010).

[24] R.L. Schalock, J.F. Gardner and V.J. Bradley, Quality of life of persons with intellectual and other developmental disabilities: applications across individuals, organizations, systems, and communities, American Association on Intellectual and Developmental Disabilities, Washington, DC (2007).

\section{BOX AND TABLES}

Box 1. The four inter-related themes with regard to providing diabetes support resulting from the analyses

\section{Person with diabetes}

- Severity of diabetes

- Capability of learning

- Motivation

\section{Professional caregiver}

- Knowledge about diabetes

- Knowledge and skills to support self-management

\section{Finding a mode}

- Support in practice: diet control and medical management $\&$ the care program

- Relationship caregiver and person with ID

- Dilemmas in support

- Responsibilities

\section{Contextual factors}

- Community housing

- Team 
Table 1

Facilitating and impeding factors related to providing diabetes support, according to the professional caregivers in this study ( $n=13$ ).

\begin{tabular}{|c|c|}
\hline Facilitating & Impeding \\
\hline Related to the person with diabetes: & Related to the person with diabetes: \\
\hline Person with diabetes is eager and able to learn & $\begin{array}{l}\text { No ability to learn new skills. Ageing has a negative influence on } \\
\text { a person's intellectual abilities and skills }\end{array}$ \\
\hline Person with diabetes is interested in own health & Person with diabetes is lazy, passive, does not value independence \\
\hline Person with diabetes indicates him/herself if something is the matter & Person with diabetes is tense, nervous, frustrated or ill-tempered \\
\hline Related to the professional caregiver: & Related to the professional caregiver: \\
\hline- & Little knowledge about diabetes and about how to support self-management \\
\hline Finding a mode: & Finding a mode: \\
\hline $\begin{array}{l}\text { A clear, structured care program with appointments related } \\
\text { to diabetes management }\end{array}$ & Caregiver does not trust person with diabetes (eating in secret, etc.) \\
\hline \multicolumn{2}{|l|}{$\begin{array}{l}\text { The needs of persons with diabetes form the basis of a self-management plan; } \\
\text { the people with diabetes are consulted and agree with the plan } \\
\text { and the goals that are set }\end{array}$} \\
\hline \multicolumn{2}{|l|}{$\begin{array}{l}\text { Providing opportunities to learn, a positive approach, put } \\
\text { one's trust in the person }\end{array}$} \\
\hline \multicolumn{2}{|l|}{$\begin{array}{l}\text { To compliment people on their efforts instead of telling them what } \\
\text { they should not have done }\end{array}$} \\
\hline Contextual: & Contextual: \\
\hline $\begin{array}{l}\text { All caregivers use a consistent approach: the team members are informed } \\
\text { and keep the appointments made in the plan }\end{array}$ & $\begin{array}{l}\text { No diabetes information brochures that people with ID can understand } \\
\text { and that can be used in the self-management support }\end{array}$ \\
\hline \multirow{2}{*}{$\begin{array}{l}\text { Collaborative approach: person with diabetes, caregivers, health professionals } \\
\text { and family work together on the same goals }\end{array}$} & Other residents in community housing who need a lot of attention \\
\hline & Material: indicator of blood glucose level does not work properly \\
\hline
\end{tabular}

Material: indicator of blood glucose level does not work properly 
Table 2

Finding a mode: different ways of support related to food intake, organized along the extent to which the individual with diabetes is involved in self-management.

\begin{tabular}{|c|c|c|}
\hline More & $\begin{array}{l}\text { Characteristics of } \\
\text { support }\end{array}$ & Examples of providing support \\
\hline $\begin{array}{l}\text { engagement and } \\
\text { development of } \\
\text { autonomy }\end{array}$ & $\begin{array}{l}\text { Initiative with person } \\
\text { with ID }\end{array}$ & $\begin{array}{l}\text { Avoid control, unless a person's health is } \\
\text { deteriorating (for example, frequent high } \\
\text { blood glucose levels) }\end{array}$ \\
\hline \multirow{4}{*}{$\begin{array}{l}\text { Little } \\
\text { engagement and } \\
\text { room for learning }\end{array}$} & $\begin{array}{l}\text { Engaged, joint } \\
\text { decision }\end{array}$ & $\begin{array}{l}\text { Informed and engaged in diabetes } \\
\text { management, appointments in care plan, call } \\
\text { someone to account in case appointments are } \\
\text { not kept, consultation and negotiation around } \\
\text { special occasions (e.g. birthday) }\end{array}$ \\
\hline & $\begin{array}{l}\text { Initiative with } \\
\text { caregivers, informed }\end{array}$ & $\begin{array}{l}\text { "Not good for you, because you have } \\
\text { diabetes" }\end{array}$ \\
\hline & & $\begin{array}{l}\text { Every day the food intake is fixed (amount, } \\
\text { choice) }\end{array}$ \\
\hline & $\begin{array}{l}\text { Initiative with } \\
\text { caregivers, control } \\
\text { and protection }\end{array}$ & $\begin{array}{l}\text { Kitchen cabinets closed, the person with } \\
\text { diabetes must eat alone, the person's private } \\
\text { room is regularly checked for hidden food or } \\
\text { snacks }\end{array}$ \\
\hline
\end{tabular}

